\title{
Copper removal from aqueous systems with coffee wastes as low-cost materials
}

\author{
G. Z. Kyzas $^{1}$, D. N. Bikiaris ${ }^{2}$, M. Kostoglou ${ }^{2}$ and N. K. Lazaridis ${ }^{2}$ \\ ${ }^{1}$ Department of Oenology and Beverage Technology, Technological Educational Institute of Kavala, GR-654 04 Kavala, \\ Greece,georgekyzas@gmail.com \\ 2 Department of Chemistry, Aristotle University of Thessaloniki, GR-541 24 Thessaloniki, Greece
}

\begin{abstract}
This work aims to study the removal of $\mathrm{Cu}$ (II) from aqueous solutions with coffee residues. Waste materials with no further treatment such as coffee residues from café may act as adsorbents for the removal of $\mathrm{Cu}(\mathrm{II})$. Equilibrium data were successfully fitted to the Langmuir, Freundlich and Langmuir-Freundlich model (L-F). The maximum adsorption capacity of the coffee residues can reach 70 $\mathrm{mg} / \mathrm{g}$ for the removal of $\mathrm{Cu}(\mathrm{II})$. The kinetic data were fitted to pseudo-first, -second and -third order equation. The equilibrium was achieved in $120 \mathrm{~min}$. Also, the effect of $\mathrm{pH}$ on adsorption and desorption was studied. Ten cycles of adsorption-desorption were carried out revealing the strong reuse potential of these low-cost adsorbents; the latter was confirmed from a brief economic approach.
\end{abstract}

Key words: Coffee residues, Heavy metals, $\mathrm{Cu}(\mathrm{II})$, Adsorption; Low-cost materials

\section{Introduction}

Heavy metals contamination of water is a serious threat to the globe ecosystem. Many industries such as metal plating, mining operation, and tanneries release wastewaters contaminated with heavy metals into the environment (Bailey et al 1999). So, their removal from contaminated waters has become a major topic of research in recent years, due to the toxicological problems caused by the metal ions to the environment and to human health. Various processes of heavy metals elimination are used, such as precipitation, electro precipitation, electro coagulation, cementing and separation by membrane, the solvent extraction and the exchange of ions on resins (Babel and Kurniawan 2003). However, these processes are not economical enough for wastewater treatment. Strict environmental protection legislation and public environmental concerns lead the global search for novel and low-cost techniques to remove heavy metals from industrial wastewater (Bailey et al 1999; Babel and Kurniawan 2003). So, recent research is directed to developing cost-effective technologies for the removal of metal ions from aqueous solutions.

Adsorption is considered quite attractive in terms of its efficiency of removal from dilute solutions. Although, the use of common materials (activated carbon (Bailey et al 1999), chitosan (Kyzas et al 2009), zeolite, clay is still very popular due to the high adsorption capacity, but there are expensive, too. Thus, there is a growing demand to find relatively efficient, low-cost and easily available adsorbents for the adsorption of cadmium, particularly if the adsorbents are the wastes. The researchers were oriented towards no expensive adsorbents which are the vegetable wastes such as: waste of tea, sawdust, the tree fern, the olive oil waste, the orange juice waste, the orange barks, the algae, plants dried and olive stone waste. However, there is a lack of literature dealing with the possible application of coffee residues as adsorbents. Under the title of "coffee residues" are generally called the solid wastes discarded from the extraction process of instant coffee manufacturing, and the final residues originated from cafeterias.

In the last years, the instant coffee industry has experienced a constant growth as instant coffee has become one of the most popular kinds of coffee drunk by million of people around the world. As a consequence, large amounts of coffee grounds, which are the solid residues obtained during the processing of coffee powder with hot water or steam to prepare instant coffee, have been generated worldwide (in the order of $6,000,000$ tons/year) (Mussatto et al 2011).

Since sustainable development should be prioritized, the development of techniques for giving additional 
value and reusing this type of residues should be sought. In view of the aforementioned, the objective of this study was to investigate the feasibility of using untreated coffee residues from cafeterias directly as natural biosorbents for the removal of heavy metals $(\mathrm{Cu}$ (II)) from synthetic aqueous media. It is a great of interest to treat heavy metal effluents with untreated natural residues. Different parameters of adsorption process were studied, such as the effect of $\mathrm{pH}$, contact time, agitation rate, ion initial concentration. Another very important factor studied was the reuse of the coffee residuals in sequential cycles of adsorption and desorption. Also, an economic approach was realized to show: (i) the feasibility/effectiveness of the coffee grounds used as potential adsorbents, and (ii) how the respective treated sample of coffee is greater and more economically feasible than the untreated sample. A useful perspective, after the batch scale modules on lab tests of the current work, will be the fixed beds in a possible next step, and later the adjustment in pilot scale tests.

\section{Materials and Methods}

\section{Materials}

The samples of coffee residues were collected after roasting a special variety of coffee drinks ( "Greek coffee" drinks) and kindly donated by a local café (Thessaloniki, Greece). Also, CuSO4 • 5H2O (Fluka, 98\% purity) and $\mathrm{K} 2 \mathrm{Cr} 2 \mathrm{O} 7$ (Fluka, puriss. p.a. $\geq 99.0 \%$ ) were used for the preparation of $\mathrm{Cu}(\mathrm{II})$ and $\mathrm{Cr}(\mathrm{VI})$ adsorbate stock solutions, respectively.

\section{Types of coffee residues}

Two types of agricultural residues coming were used in the current work: (i) Untreated Coffee Residues (abbreviated hereafter as UCR) from cafeterias and constitute a waste (without no further treatment, just only dried at the ambient air and then sieved); (ii) Treated Coffee Residues (abbreviated hereafter as TCR), which were washed with distilled water to remove dirt and colour, and dried at $105 \mathrm{oC}$ for $5 \mathrm{~h}$ in a convection oven. They were then treated with $2 \%$ formaldehyde solution in order to reduce organic leaching and avoid mould formation during batch adsorption (Boonamnuayvitaya et al 2004). Both two types of residues were in powder form $(475-525 \mu \mathrm{m})$ after sieving.

\section{Adsorption-desorption experiments}

The effect of $\mathrm{pH}$ was conducted by mixing $1 \mathrm{~g} / \mathrm{L}$ of adsorbent with $50 \mathrm{~mL}$ metal single-component solution $(50 \mathrm{mg} / \mathrm{L})$. The $\mathrm{pH}$ value, ranging between 2 and 12, was kept constant throughout the adsorption process by micro-additions of HNO3 $(0.01 \mathrm{M})$ or $\mathrm{NaOH}(0.01 \mathrm{M})$. The suspension was shaken for $24 \mathrm{~h}$ (agitation rate $=140$ $\mathrm{rpm}$ ) into a water bath to control the temperature at $25{ }^{\circ} \mathrm{C}$ (Julabo SW-21C). The optimum $\mathrm{pH}$ selected was $\mathrm{pH}=5$ both for $\mathrm{Cu}(\mathrm{II})$ and $\mathrm{Cr}(\mathrm{VI})$.

Kinetic experiments were performed by mixing 1 $\mathrm{g} / \mathrm{L}$ of sorbent with $50 \mathrm{~mL}$ metal single-component solution $(50 \mathrm{mg} / \mathrm{L})$. The suspensions were shaken for 24 $\mathrm{h}$ at $\mathrm{pH}=5$ (both for $\mathrm{Cu}(\mathrm{II})$ and $\mathrm{Cr}(\mathrm{VI})$ ) in water bath at $25^{\circ} \mathrm{C}$ (agitation rate $=140 \mathrm{rpm}$ ). Samples were collected at fixed intervals $(5,10,20,30 \mathrm{~min}, 1,2,3,4,5,6,12$, $24 \mathrm{~h}$ ). Pseudo-first, -second, and -thrid order equations were selected to fit the experimental

The effect of initial metal (single-component) concentration on equilibrium was realized by mixing 1 $\mathrm{g} / \mathrm{L}$ of adsorbents with $50 \mathrm{~mL}$ of metal solutions of different initial concentrations $(0-150 \mathrm{mg} / \mathrm{L})$. The suspensions were shaken for $24 \mathrm{~h}$ at $\mathrm{pH}=5$ in water bath at $25^{\circ} \mathrm{C}$ (agitation rate $\left.=140 \mathrm{rpm}\right)$.

The resulted equilibrium data were fitted to the Langmuir, Freundlich and Langmuir - Freundlich (L-F) isotherm. The amount of total metal uptake at equilibrium Qe $(\mathrm{mg} / \mathrm{g})$ was calculated using the mass balance equation:

$$
\mathrm{Q}_{\mathrm{e}}=\frac{\left(\mathrm{C}_{0}-\mathrm{C}_{\mathrm{e}}\right) \mathrm{V}}{\mathrm{m}}
$$

where $\mathrm{m}(\mathrm{g})$ is the mass of adsorbent; $\mathrm{V}(\mathrm{L})$ the volume of adsorbate; $\mathrm{C} 0$ and $\mathrm{Ce}(\mathrm{mg} / \mathrm{L})$ are the initial and equilibrium metal concentrations (single-component) in the liquid phase, respectively.

After the adsorption experiments (where the coffee residues were exposed to $50 \mathrm{mg} / \mathrm{L}$ of metal single-component solution at $25{ }^{\circ} \mathrm{C}$ at $\mathrm{pH}=5$, the samples were collected and filtered, using fixed pore-sized membranes. A small fraction of the metals (1-2\%) and the adsorbent $(1 \%)$ were retained on the filter membrane; these small variations due to filtration were neglected. Desorption experiments were realized by mixing the collected, after adsorption, amount of metal-loaded coffee residues $(0.05 \mathrm{~g})$ with aqueous solutions of $50 \mathrm{~mL}$ (same volume as in the adsorption step) over a $\mathrm{pH}$ range between 2 and 12 , at $25{ }^{\circ} \mathrm{C}$ for $24 \mathrm{~h}$ (agitation rate $=140$ $\mathrm{rpm})$. This procedure was realized to determine the optimum desorption $\mathrm{pH}$ value of the metal-loaded adsorbents. To determine the reusability of the coffee residues, 10 sequential adsorption-desorption cycles were repeated, using the same adsorbents and following the experimental procedures described above in the optimum conditions found.

\section{Analysis}

Samples of the solution of $\mathrm{Cu}(\mathrm{II})$ were analyzed by atomic absorption spectroscopy, using an Atomic Absorption Spectrophotometer (Perkin - Elmer AAnalyst 400) composed of FIAS 100 Flow Injection System. Due to the sensitivity of the instrument, the samples with high residual ion concentrations were diluted before the measurement. The aforementioned dilution was taken into account for all the calculations. 


\section{Results and Discussion}

\section{Effect of $p H$ on adsorption}

It was observed that the adsorption percentages are very low at strong acidic medium. At $\mathrm{pH}=2$, the removal percentages were $15 \%$ in the case of $\mathrm{Cu}(\mathrm{II})$. After $\mathrm{pH}=3$ $(\mathrm{Cu}(\mathrm{II}): 60 \%)$, uptakes increase sharply up to $\mathrm{pH}=5$ (Cu(II): 76\%), and thereafter they stay almost constant for higher $\mathrm{pHs}$. No $\mathrm{pH}$ values over 8 were studied since precipitation of heavy metals dominates.

The optimum $\mathrm{pH}$ selected for further adsorption experiments (kinetics, isotherms etc) was 5. This was exported by considering and adopting some limitations, as: (i) copper introduces a limiting $\mathrm{pH}$ value of 5 , above which its precipitation begins in the form of insoluble hydroxide (Nuhoglu and Oguz 2003; Mohan et al 2005); (ii) on the idea of working in a condition close to that naturally established by the medium, thus, not requiring significant modifications. Other researches, who have studied the effect of $\mathrm{pH}$ on metal removal with coffee residues, studied the adsorption phenomenon in the optimum $\mathrm{pH}$ range 4-5, too (Djati Utomo and Hunter 2006; Oliveira et al 2008; Azouaou et al 2010).

\section{Effect of contact time}

Fig. 1 depicts the effect of contact time on the adsorption behavior of low-cost material used.

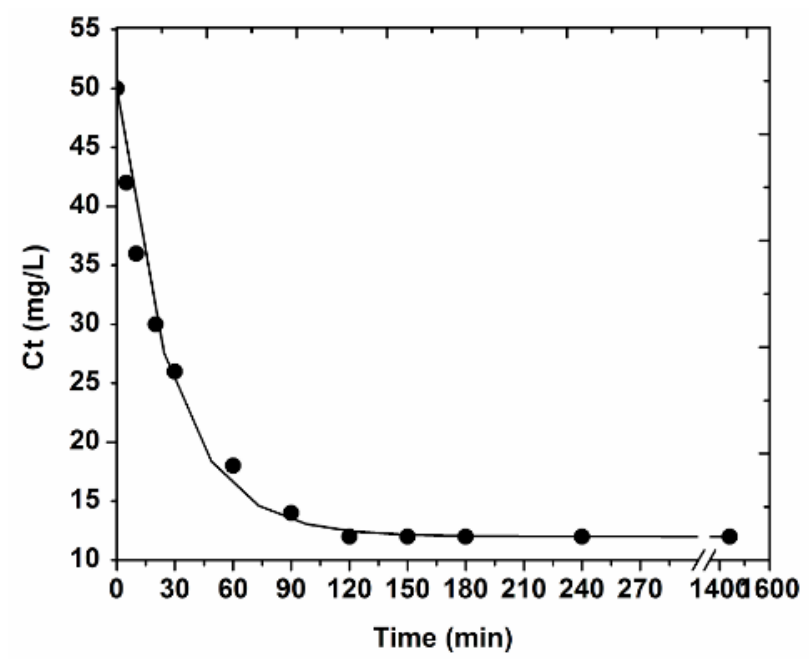

Fig. 1. Effect of contact time on adsorption of $\mathrm{Cu}$ (II) onto coffee residues.

The plots could be split in three distinct regions: (i) 0-20 min, which indicates the instantaneous adsorption of ions, suggesting rapid external diffusion and surface adsorption; (ii) 20-180 min, shows a gradual equilibrium, and (iii) 3-24 h, indicates the equilibrium state (Wang and Wang 2008).

After fitting, kinetic parameters resulted by fitting the pseudo-first, -second and -third order equation to the experimental data revealed useful findings. According to the correlation coefficients $\left(\mathrm{R}^{2}\right)$ exported, the best fitting was for the pseudo-first order equation $\left(0.994<\mathrm{R}^{2}<0.998\right)$, while the pseudo-second $\left(0.963<\mathrm{R}^{2}<0.972\right)$ and pseudo-third $\quad\left(0.872<\mathrm{R}^{2}<0.889\right) \quad$ order equations presented enough lower coefficients.

\section{Effect of initial metal concentration}

The values of correlation coefficient $\left(\mathrm{R}^{2} \sim 0.998\right)$ after fitting in three models, which is an indication of the goodness of fitting, confirm that the L-F model results in closer prediction of the isotherm compared with the experimental data. The effect of initial metal concentration on the adsorption metal loading of the coffee residues is graphically given by Fig. 2 .

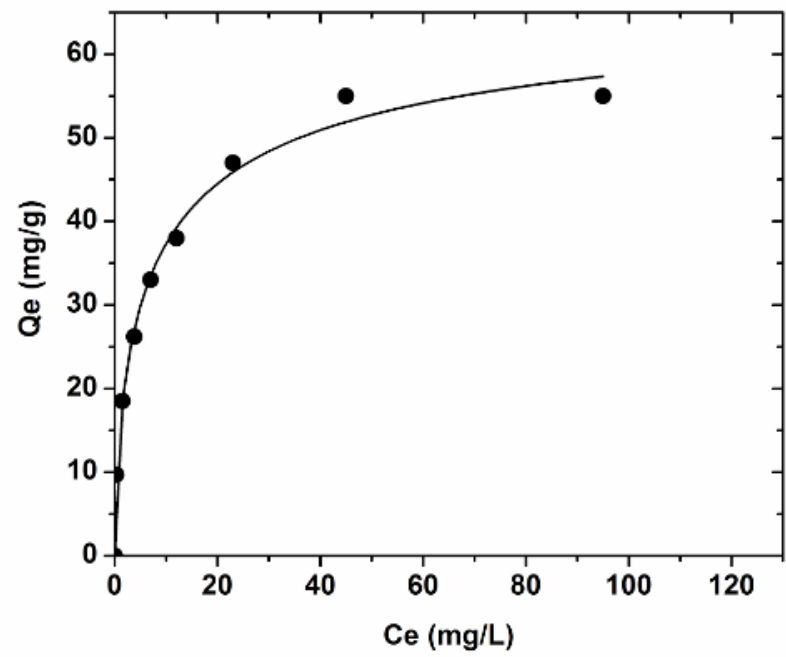

Fig. 2. Effect of initial ion concentration on adsorption of $\mathrm{Cu}$ (II) onto coffee residues.

Typical adsorption isotherms were observed for both powder and beads materials. Data showed an increase in the amount of metal adsorbed onto the coffee adsorbents, when the initial metal concentration was increased.

\section{Desorption and reuse}

A further goal of any adsorbent used is the reuse potential. So, before the investigation of the reuse, desorption experiments were carried out to find the optimum $\mathrm{pH}$-desorption conditions. For $\mathrm{Cu}(\mathrm{II})$ the strong acidic conditions favour the desorption of metals at high percentages $(\mathrm{Cu}(\mathrm{II}), 94 \%)$. In contrast, in alkaline conditions the desorption is taking place in low percentages $(\mathrm{Cu}(\mathrm{II}), 21 \%)$. So, the $\mathrm{pH}$ value selected for the further reuse experiments (adsorption-desorption cycles) was $\mathrm{pH}=2$.

To investigate the possibility of reuse of the low-cost materials of the current study, sequential adsorption-desorption experiments in batch mode were conducted for ten cycles. It was observed that the reduction in adsorption percentages from the 1 st to 10 th cycle was $6 \%$ for $\mathrm{Cu}(\mathrm{II})$. The decrease of the adsorption efficiency occurred can be attributed to several reasons as: (i) a progressive saturation of the active sites/groups of 
the adsorbent by metal ions, and (ii) a degradation of material due to extreme $\mathrm{pH}$ conditions. In addition, a progressive blocking of the active sites of the adsorbent by impurities in the case of untreated coffee residues caused a slight decrease in the adsorption potential compared to the treated ones. In the cases of low-cost materials used as adsorbents and especially for copper removal with coffee residues, the loss of their adsorptive ability is characterized as enough low, very sufficient for further repeated use (Bailey et al 1999).

\section{Economic perspectives}

The coffee residues used in the study is the result after the roasting of a special variety of coffee (Greek coffee). To have a more comparative view, apart from the untreated form (just dry), a slight modification was realized to obtain a more pure form. However, according to the experimental data, the changes in the crucial factors of adsorption ( $\mathrm{Q}_{\max }$, adsorption) and reuse (cycles) were only slight, and easily can be neglected. Also, the regeneration step of these adsorbents is easy. They can be regenerated by desorption at low cost if required. They are easily regenerated by a washing solvent since the interaction between the pollutant and adsorbent is driven mainly by electrostatic, hydrophobic and ion-exchange interactions. The desorption side of the process gives the pollutant in a concentrated form and restores the material close to the original condition for effective reuse with no physical-chemical changes or damage. The regeneration of saturated carbon by thermal and chemical procedure is known to be expensive, and results in loss of the adsorbent. The adsorption properties are also reproducible. After saturation, the adsorption capacity value remains unchanged.

Practically and numerically, there are coffee residues with no further use in nutrition cycle (coffee) which can be used and re-used up to 10 times adsorbing approximately $70 \mathrm{mg}$ of $\mathrm{Cu}(\mathrm{II})$ per gram. This is directly comparative with other examples of coffee residues, where the cost of preparation was higher. According to Baek et al (2010), the comparison between the cost of the use of activated carbon and low-cost materials is up to 15 times larger. Given a gross estimation of the economic superiority is the cost of use of the two common materials for metal adsorption; Activated Charcoal Norit ROX $125.5 € / \mathrm{kg}$ (Fluka 2010) and chitosan 7-28€/kg. Taking into consideration that the coffee residues of the current study has nearly zero cost (for the untreated form), there is a great potential to further and continuous use in bed columns or possible pilot scale.

\section{Conclusions}

In this study, coffee residues were used as low-cost adsorbents for the removal of $\mathrm{Cu}(\mathrm{II})$ from aqueous solutions. The $\mathrm{pH}$ selected as optimum for further adsorption experiments was $\mathrm{pH}=5$, where the adsorbents presented the maximum removal just before the $\mathrm{pH}$-zone of 5-8 where precipitation and hydrolysis phenomena dominate. Equilibrium data were fitted to the Langmuir, Freundlich and Langmuir-Freundlich (L-F) model. The best correlation was for L-F model $\left(\mathrm{R}^{2} \sim 0.998\right)$. Kinetic data were fitted to the pseudo-first, -second and -third order model. The best correlation was for pseudo-first order equation $\left(\mathrm{R}^{2} \sim 0.996\right)$. The optimum $\mathrm{pH}$ found after desorption experiments was $\mathrm{pH}=2$ for $\mathrm{Cu}(\mathrm{II})$. After 10 cycles of adsorption-desorption, the reduction in adsorption percentages from the 1 st to 10 th cycle was approximately $7 \%$.

\section{Acknowledgements}

The authors gratefully acknowledge the local café "Bliss" (Thessaloniki, Greece), which kindly donated the real residues of coffee (collected after roasting a special variety of coffee drinks, "Greek coffee" drinks).

\section{References}

APHA, AWWA, WPCF (1995). Standard Methods for the Examination of Water and Wastewater. 20th ed., American Public Health Association, Washington, DC, USA, p. 20005.

Azouaou, N., Sadaoui, Z., Djaafri, A., Mokaddem, H. (2010). Adsorption of cadmium from aqueous solution onto untreated coffee grounds: Equilibrium, kinetics and thermodynamics. Journal of Hazardous Materials, 184, 126-134.

Babel, S., Kurniawan, T.A. (2003). Low-cost adsorbents for heavy metals uptake from contaminated water: A review. Journal of Hazardous Materials 97, 219-243.

Baek, M.-H., Olakitan Ijagbemi, C., O, S.-J., Kim, D.-S. (2010). Removal of malachite green from aqueous solution using degreased coffee bean. Journal of Hazardous Materials 176, 820-828.

Bailey, S.E., Olin, T.J., Brick, R.M., Adrian, D.D. (1999). A review of potentially low-cost sorbents for heavy metals. Water Research, 33, 2469-2479.

Balistrieri, L.S., Murray, J.W. (1981). The surface chemistry of goethite $(\alpha \mathrm{FeOOH})$ in major ion seawater. American Journal of Science, 281, 788-806.

Djati Utomo, H., Hunter, K.A. (2006). Adsorption of heavy metals by exhausted coffee grounds as a potential treatment method for waste waters. e-Journal of Surface Science and Nanotechnology, 4, 504-506.

Ho, Y.S., Ng, J.C.Y., McKay, G. (2000). Kinetics of Pollutant Sorption by Biosorbents: Review. Separation and Purification Methods, 29, 189-232.

Kinniburgh, D.G. (1986). General purpose adsorption isotherms. Environmental Science and Technology, 20, 895-904.

Kyzas, G.Z., Kostoglou, M., Lazaridis, N.K. (2009). Copper and chromium(VI) removal by chitosan derivatives-Equilibrium and kinetic studies. 
Chemical Engineering Journal, 152, 440-448.

Mohan, D., Singh, K.P., Singh, V.K. (2003). Removal of hexavalent chromium from aqueous solutions using low-cost activated carbons derived from agricultural waste materials and activated carbon fabric cloth. Industrial Engineering Chemical Research, 44, 1027-1042.

Mussatto, S.I., Machado, E.M.S., Martins, S., Teixeira, J.A. (2011). Production, composition and application of coffee and its industrial residues. Food and Bioprocess Technology, 4, 661-672.

Nuhoglu, Y., Oguz, E. (2003). Removal of copper(II) from aqueous solutions by biosorption on the biomass of Thuja orientalis. Process Biochemistry,
38, 1627-1631.

Oliveira, W.E., Franca, A.S., Oliveira, L.S., Rocha, S.D. (2008). Untreated coffee husks as biosorbents for the removal of heavy metals from aqueous solutions. Journal Hazardous Materials, 152, 1073-1081.

Prasanna Kumar, Y., King, P., Prasad, V.S.R.K. (2006). Equilibrium and kinetic studies for the biosorption system of copper(II) ion from aqueous solution using Tectona grandis L.f. leaves powder. Journal of Hazardous Materials, 137, 1211-1217.

Wang, L., Wang, A. (2008). Adsorption properties of congo red from aqueous solution onto N,O-carboxymethyl-chitosan. Bioresource Technology, 99 1403-1408. 